\title{
USING GAUSSIAN PROCESSES TO STUDY TRAUMATIC BRAIN INJURY IN SHEEP
}

\author{
LEVON GABRIELIAN ${ }^{1}$, NOUNE S. MELKOUMIAN ${ }^{2}$, MAGDALENA CUCIUREANU $^{3 *}$ \\ ${ }^{I}$ Schools of Medical Sciences, University of Adelaide, and Hanson Institute Centre for Neurological Diseases, Australia \\ ${ }^{2}$ School of Civil, Environmental, and Mining Engineering, University of Adelaide, Australia \\ 3 "Grigore T. Popa" University of Medicine and Pharmacy, Faculty of Medicine, Department of Morphofunctional Sciences, \\ Iași, Romania
}

*corresponding author: mag.cuciureanu@umfiasi.ro

Manuscript received: July 2019

\begin{abstract}
The aim of this study was to investigate the dynamic interrelationship between brain tissue oxygenation (PbtO2), intracranial pressure (ICP), mean arterial blood pressure (MABP), and cerebral perfusion pressure (CPP) in an acute sheep model of traumatic brain injury (TBI). PbtO2, ICP, MABP, and CPP were monitored after TBI. Gaussian Processes for machine learning has been used to do simultaneous 3D analysis of the dynamic interrelationship between these parameters. Two critical thresholds for ICP after TBI were identified during our experiments that correlated to human data and may correlate to different intravascular hydrostatic pressures in two different sections of cerebral vasculature. Simultaneous 3D analysis of the dynamic interrelationship between $\mathrm{PbtO} 2$ vs. ICP and MABP or CPP could be a better method as opposed to 2-parameter ( $\mathrm{PbtO} 2$ vs. ICP or CPP) analysis. Current CPP formula may not always reflect the actual cerebral perfusion, therefore we propose the formula as: $\mathrm{CPP}=\mathrm{PAP}$ - ICP, where $\mathrm{PAP}$ is the post arteriolar pressure.
\end{abstract}

\section{Rezumat}

Investigarea relației dinamice între oxigenarea tisulară cerebrală (PbtO2), presiunea intracranială (ICP), tensiunea arterială medie (MABP), și presiunea de perfuzie cerebrală (CPP) într-un model experimental ovin de traumatism cerebral acut (TBI). $\mathrm{PbtO} 2$, ICP, MABP și CPP au fost monitorizate timp de 4 ore după producerea TBI. Procesul gaussian de învațare automată a fost utilizat pentru analiza simultană 3D a interrelației dinamice între PbtO2, ICP și MABP. S-au identificat două valori prag pentru ICP care au corespuns cu datele clinice și care se pot corela cu presiuni hidrostatice intravasculare distincte în două sectoare vasculare cerebrale diferite. Analiza simultană 3D a interrelației dinamice între $\mathrm{PbtO} 2$ vs. ICP și MABP ori CPP poate reprezenta o metodă superioară comparativ cu analiza bazată pe 2 parametri ( $\mathrm{PbtO} 2$ vs. ICP ori $\mathrm{CPP})$. Formula curentă privind CPP nu reflectă întotdeauna perfuzia cerebrală reală şi de aceea propunem formula CPP $=$ PAP - ICP, unde PAP este presiunea post arteriolară.

Keywords: TBI; ICP; PbtO2; MABP; CPP formula; Gaussian Processes

\section{Introduction}

Traumatic brain injury (TBI) causes more death and disability than any other disease in population up to 45 years of age in Western industrialized countries [3, $13,14,18]$ with the main causes being motor vehicle accidents and falls, and in some countries also assaults and some sport activities [23]. It is estimated, that globally, by the year 2020, severe TBI will be the third most common cause of death and disability [30,54]. Brain damage caused by the acute primary injury evolves with time as secondary injury producing complex structural and pathophysiological changes including cerebral hypoxia, ionic and acid-base disturbances, cerebral oedema, intracranial hypertension and hypotension [5, 20, 56, 61].

Clinical and experimental studies have shown that cerebral hypoxia is associated with a poor outcome after moderate to severe TBI, thus making possible optimal brain tissue oxygenation crucial for the outcome of patients with TBI [1, 31]. Post TBI brain oedema plays a vital role in the development of cerebral hypoxia, since it increases ICP and thus decreases cerebral perfusion and oxygenation by expanding brain tissue volume according to the Monro-Kellie doctrine. Therefore the front line approach to maintaining adequate cerebral oxygenation in neuro-critical care is to maintain adequate cerebral perfusion pressure (CPP), usually achieved by controlling increased ICP and MABP $[1,12]$. However it is still not fully understood how ICP, MABP, CPP, and $\mathrm{PbtO} 2$ are interrelated, and elucidating the dynamic interrelationship between these parameters after TBI may provide new strategies to improving outcome after TBI. Therefore, to study the dynamics between $\mathrm{PbtO} 2$, ICP, MABP, and CPP at different injury severities, we have chosen to analyse the correlation between $\mathrm{PbtO} 2$, ICP, and MABP or CPP simultaneously. To do so in the present study we have used Gaussian Processes (GPs) for 
machine learning, which calculates an interconnected 3-D analysis of the parameters influencing PbtO2. Conversely it is well known that increased ICP by itself (and not CPP) is an independent predictor of outcome in patients with severe TBI and uncontrolledelevated ICP is considered to be the primary cause of death in more than a half of all patients with TBI [26, 27, 40, 55]. Moreover, clinical and experimental studies have shown that ICP has two distinctive thresholds, that is $20-25 \mathrm{mmHg}[17,24,27,39,48]$ and $35-40 \mathrm{mmHg}[24,37,45,46,55]$ being considered critical for patient's good or poor outcome and life threatening respectively. These findings are not fully understood so far [9, 19, 42, 52]. Furthermore ICP measurement is important because it allows both an early detection of evolving mass lesions and for the calculation of CPP.

$\mathrm{CPP}$ is calculated as the difference between MABP and ICP; CPP = MABP - ICP. Although, maintaining adequate $\mathrm{CPP}$ is important to ensure sufficient $\mathrm{PbtO} 2$, it does not reflect the actual values of ICP and MABP, which partially explains how patients with TBI can have profoundly different outcomes with the same CPP [8, 22, 52]. Specifically, equivalent changes in ICP and MABP, either in a positive or negative direction, will not be reflected in CPP values, and hence a focus on CPP may overlook critical changes in ICP and MABP. It is therefore not surprising that the optimal CPP after TBI accordingly remains unknown $[22,41]$. In contrast, $\mathrm{PbtO} 2$ based therapy has been associated with more favourable outcomes and, so far, clinical studies suggest that combined ICP/CPP and $\mathrm{PbtO} 2$ based therapy is associated with better outcomes after TBI than ICP/CPP based therapy alone [49-51]. In terms of what the $\mathrm{PbtO} 2$ values represent, values between 20 - $50 \mathrm{mmHg}$ are regarded as normal; $\mathrm{PbtO} 2$ values below 20 but above $15 \mathrm{~mm}$ $\mathrm{Hg}$ are considered moderately hypoxic, $\mathrm{PbtO} 2$ below $10-15 \mathrm{mmHg}$ is considered severely hypoxic and associated with the worse outcome, while $\mathrm{PbtO} 2 \leq 6$ $\mathrm{mmHg}$ is critical and life threatening [32, 43, 49, 57, 59]. Unfortunately, the nature and effectiveness of most commonly used interventions to correct compromised $\mathrm{PbtO} 2$ after TBI still remains unclear [35].

Autoregulation is an important neuroprotective mechanism that varies arteriolar calibre with changes in MABP to maintain a relatively constant cerebral blood flow (CBF). Normally, autoregulation is active within a MABP range of $50-150 \mathrm{mmHg}$ [32] and responds within seconds of the blood pressure changing [34]. When the CPP formula was initially proposed, it was based on the assumption that autoregulation had essentially failed after TBI, and that cerebral blood flow (CBF) was accordingly linearly related to MABP [9]. However, later studies have shown that pressure autoregulation is maintained in the majority of patients with severe TBI, and even more in patients with moderate TBI $[9,36]$. When autoregulation is intact, increases in CPP lead to compensatory vasoconstriction to maintain a stable CBF and so decrease the cerebral blood volume and therefore lower the ICP [41]. However, outside of the limits of pressure autoregulation, increases in CPP lead to vasodilatation, an increased blood volume and so it raises the ICP. Lowering CPP under conditions of failed autoregulation may increase the secondary cerebral hypoxia within a range of MABP that normally would have been regarded as acceptable [12]. Therefore, depending on whether cerebral autoregulation is preserved or not, an increase in CPP may result in either lowered or raised ICP. It follows that the status of autoregulation will influence the choice of whether CPP or ICP directed management should be pursued [11, 21].

In order to improve patient outcome, it is therefore critical to understand the interrelationships between MABP, ICP, CPP, and $\mathrm{PbtO} 2$ under varying conditions following moderate to severe TBI. The aim of this study is to investigate the dynamics of these interrelationships using machine learning 3-D analysis by a Gaussian process, so as to investigate the two critical thresholds of ICP observed clinically and to critically assess the formula for CPP.

\section{Materials and Methods}

\section{Animals}

All experimental protocols were conducted according to the guidelines established by the Australian National Health and Medical Research Council for the use of animals in experimental research and were approved by the Animal Ethics Committee of the Institute of Medical and Veterinary Science and the University of Adelaide, Australia.

Two-year-old, sterilized male Merino sheep ( $\mathrm{n}=57$; $52 \pm 5 \mathrm{~kg}$ ) were injured using the humane stunner as described in detail elsewhere [25]. Briefly, animals were anesthetized by an intravenous injection of thiopentone before intubation and ventilation $(4 \mathrm{~L} /$ min) with oxygen enriched (30 - 35\%) air containing $2.5 \%$ isoflurane. A femoral arterial catheter was then implanted to continuously monitor the mean arterial blood pressure (MABP) using a MacLab data acquisition system (MacLab 2e). After the placement of the catheter, isoflurane was lowered to $1.0-1.5 \%$ and an intravenous infusion of Ketamine ( $4 \mathrm{mg} / \mathrm{kg}$ bw/h) was initiated, thus providing an adequate level of anaesthesia for surgery with intact cardiovascular reflexes. Temperature was maintained using a thermostatically controlled heating pad while ventilation parameters were adjusted as necessary on the basis of arterial blood sampled at regular intervals for gas analysis. To induce TBI, sheep were placed into a prone sphinx position, with the torso restrained to the surgical table leaving the neck and head mobile relative to the body. Impact acceleration injury was induced at the midpoint between the left supraorbital process 
and the left external auditory meatus using a captive humane bolt stunner armed with a number 17 red, dry, charge (model KML, Karl Schermer \& Co., Germany). This impact causes a characteristic diffuse axonal injury $[25,58]$. After TBI and insertion of probes each animal was monitored for 4 hours.

\section{Intracranial pressure monitoring}

Following the exposure of the skull, a $2.5 \mathrm{~mm}$ burr hole was performed at a point $15 \mathrm{~mm}$ lateral to the sagittal midline on the ipsilateral side just in front of the coronal suture. A $1.73 \mathrm{~mm}$ diameter catheter was fixed into the burr hole, the dura matter opened and a calibrated Codman Microsensor ICP transducer inserted such that the tip of the sensor was $1.5 \mathrm{~cm}$ into the parenchyma of the left parietal lobe. The probe was attached to a Codman ICP Express monitoring system (Codman and Shurtleff Inc., USA) which was linked to an ADInstruments PowerLab ${ }^{\circledR}$ system where the data was digitally recorded.

Cerebral tissue oxygenation monitoring

A second burr hole $1.5 \mathrm{~cm}$ lateral to the sagittal midline and over the left fronto-parietal suture allowed insertion of a $\mathrm{LICOX}^{\circledR} \mathrm{PbtO} 2$ probe to a depth of $3.5 \mathrm{~cm}$. The LICOX $^{\circledR}$ probe, which contained an integrated brain temperature sensor, was attached to a LICOX ${ }^{\circledR}$ brain tissue oxygen monitoring system (Integra, USA) for digital recording. After insertion of the probes, both burr holes were sealed using bone wax.

\section{Mean arterial blood pressure monitoring}

Mean arterial blood pressure was monitored with a MacLab data acquisition system (MacLab 2e). The animal femoral artery catheter was connected to a Statham-type pressure transducer and the arterial blood pressure was continuously recorded via a MacLab data acquisition unit connected to a laptop computer running LabChart. The pressure data was relayed from the transducer to the MacLab via a bridge amp. In addition data was collected manually every $15 \mathrm{~min}$. Arterial blood gas analysis

The Osmotech OPTI blood gas analyser (CCA, Helena Laboratories, Australia Pty Ltd) was used for arterial blood gas analysis. Arterial blood samples (0.6 - 0.7 $\mathrm{mL}$ ) were obtained via the femoral arterial cannula using 3-way tap connecting the cannula with the transducer. Arterial blood gas analysis was conducted 5 times during each experiment. The first analysis was performed $10 \mathrm{~min}$ before the injury, and other four analysis were performed every hour after the injury.

Cerebral perfusion pressure monitoring

Cerebral perfusion pressure (CPP) was calculated by the equation: $\mathrm{CPP}=\mathrm{MABP}$ - ICP. CPP was monitored and recorded using the same MacLab data acquisition system, used for ICP and MABP data recording.

Statistical analysis via Gaussian Processes

The data was analysed using Gaussian processes for machine learning. The values of $\mathrm{PbtO} 2$ are represented as Gaussian predictive distributions with mean and standard deviation automatically identified from the experimental data. Log marginal likelihood is used to determine the hyper-parameters of the Gaussian process. The mean prediction represents the general trend of $\mathrm{PbtO} 2$ while the uncertainty of the prediction is expressed by the standard deviation. An error histogram is calculated to evaluate the qualities of the predictive model.

\section{Machine Learning via Gaussian Processes}

Gaussian Processes (GPs) is a statistical machine learning tool which provides means for building automated systems that can accumulate and fuse information from different sources, build concise model of the underlying hidden properties of the data and provide estimation with corresponding uncertainties for new situations [38]. GPs represents a non-parametric statistical kernel machine method and uses a covariance function for non-linear data modelling.

GPs are non-parametric models where a Gaussian process prior over function values is directly applied. In a more formal way, in a Gaussian process the function outputs $f\left(\mathrm{x}_{\mathrm{i}}\right)$ are a collection of random variables indexed by the inputs $\mathrm{x}_{\mathrm{i}}$. Any finite subset of outputs has a joint multivariate Gaussian distribution. Given a set of training inputs $\left\{\mathrm{x}_{\mathrm{i}}\right\},\left\{\mathrm{y}_{\mathrm{i}}\right\}$, the joint prior distribution of the corresponding function outputs $\left\{f_{\mathrm{i}}\right\}$ is Gaussian with zero mean and covariance matrix $K$. The GPs is entirely determined by the covariance function $K\left(\mathrm{x}, \mathrm{x}^{\prime}\right)$ and its hyper-parameters $\theta$.

A popular choice for the covariance function $K\left(\mathrm{x}, \mathrm{x}^{\prime}\right)$ is the squared exponential covariance function defined as:

$$
K\left(x, x^{\prime}\right)=\sigma_{0}^{2} \exp \left(-\frac{\left(x-x^{\prime}\right)^{T} \Sigma\left(x-x^{\prime}\right)}{2}\right),
$$

where $\Sigma$ and $\sigma_{0}$ are the hyper-parameters of the covariance function. Here $\Sigma$ is a $D \times D$ matrix and $\sigma_{0}$ is a constant, where $D$ stands for the dimensionality of the data. To reduce the computational cost, one can consider the case when $\Sigma$ is diagonal:

$$
\Sigma=\operatorname{diag}\left(\frac{1}{l_{1}^{2}}, \frac{1}{l_{2}^{2}}, \ldots, \frac{1}{l_{D}^{2}}\right),
$$

In the case of Eq. (2) the hyper-parameters $I_{1}, I_{2}$, $\ldots, I_{D}$ are the depict length-scales of the covariance function. In the expression (1) the hyper-parameter $\sigma_{0}$ characterizes the amplitude and $I_{1}, I_{2}, \ldots, I_{D}$ characterize the characteristic lengths of correlation of the functions generated by the GPs.

The choice of the hyper-parameters $\theta$ requires a nonlinear optimization step. The optimization is conducted by maximizing the log of the marginal likelihood of the data:

$$
\operatorname{lml}=-\frac{\mathbf{y}^{T} K_{y}^{-1} \mathbf{y}}{2}-\frac{\log \left|K_{y}\right|}{2}-\frac{N}{2} \log 2 \pi,
$$


Where $K_{\mathrm{y}}=K(X, X)+\sigma^{2} I$ is the covariance matrix for the targets $\mathrm{y}$. The log of the marginal likelihood has three terms: data fit; complexity penalty (based on the Occam's Razor principle) and normalization constant.

Once the optimal values for all the hyperparameters $\theta$ are determined, the GPs model allows predicting the values of the function $f(\mathrm{x})$ at new locations $\left\{\mathrm{X} *_{\mathrm{i}}\right\}$. This is done by conditioning the joint Gaussian distribution for the observed points $\left\{x_{i}\right\}$ on the data $\left\{y_{i}\right\}$ available in the given dataset. The result is a new Gaussian multivariate distribution $N(m, S)$ with mean $m$ and variance $S$ where:

$$
\begin{gathered}
m=K\left(X_{*}, X\right)\left[K(X, X)+\sigma^{2} I\right]^{-1} \mathbf{y} \\
S=K\left(X_{*}, X_{*}\right)-K\left(X_{*}, X\right)\left[K(X, X)+\sigma^{2} I\right]^{-1} K\left(X, X_{*}\right)+\sigma^{2} I
\end{gathered}
$$

GPs can be used for both regression and classification tasks and can successfully model datasets of different complex systems $[2,16,53]$. In the case of regression, the Gaussian process is provided with a set of inputoutput pairs (the training dataset) which is used to learn the hyper-parameters of the covariance function. In the case of classification, an input pattern is being assigned to one of multiple classes. Contrary to other methods which provide only a guess at the class label, GPs make predictions for classes and also provide corresponding probabilities (and therefore confidence levels) for this guess. In a practical application one may well seek a class guess, which can be obtained as the solution to a decision problem, involving the predictive probabilities as well as a specification of the consequences of making specific predictions (the loss function).

A GPs is also a best unbiased linear estimator. For more information on Gaussian processes and covariance function see Rasmussen and Williams [38] and Seeger [44].

\section{Results and Discussion}

Dynamic correlation between $\mathrm{PbtO} 2, \mathrm{ICP}$ and MABP The simultaneous 3-D analysis of the dynamic correlation between the values of $\mathrm{PbtO} 2$, ICP and
MABP (Figure 1) demonstrated several features. $\mathrm{PbtO} 2$ was within the normal range when ICP was below 5 $\mathrm{mmHg}$ and MABP was within the range of $40-160$ $\mathrm{mmHg}$. Similarly, PbtO2 was within normal range when ICP was between $5-10 \mathrm{mmHg}$, and MABP was within the range of $80-160 \mathrm{mmHg}$. When ICP was between 10 - $20 \mathrm{mmHg}, \mathrm{PbtO} 2$ was normal when MABP was between $90-150 \mathrm{mmHg}$. When ICP was between 20 - $25 \mathrm{mmHg}, \mathrm{PbtO} 2$ was borderline normal only when MABP was within the range of $100-125 \pm 5 \mathrm{mmHg}$. When MABP was below or above this range, the brain tissue was already hypoxic with $\mathrm{PbtO} 2$ values below $20 \mathrm{mmHg}$. $\mathrm{PbtO} 2$ became critical when ICP was between $30-40 \mathrm{mmHg}$, and life threatening when ICP was above $40-45 \mathrm{mmHg}$, regardless of MABP values. We have developed a contour plot that was calculated using the same data, and expressed as a 2-D chart. Additionally it shows different constant values of $\mathrm{PbtO} 2$ in curves for varying values of ICP and MABP (Figure 2). The chart also includes white arrows with different angles, the slope of which shows the significance of changes of ICP or MABP on PbtO2 changes. Thus the chart potentially can facilitate the management of $\mathrm{PbtO} 2$ during critical care monitoring once its analogue is developed using human data.

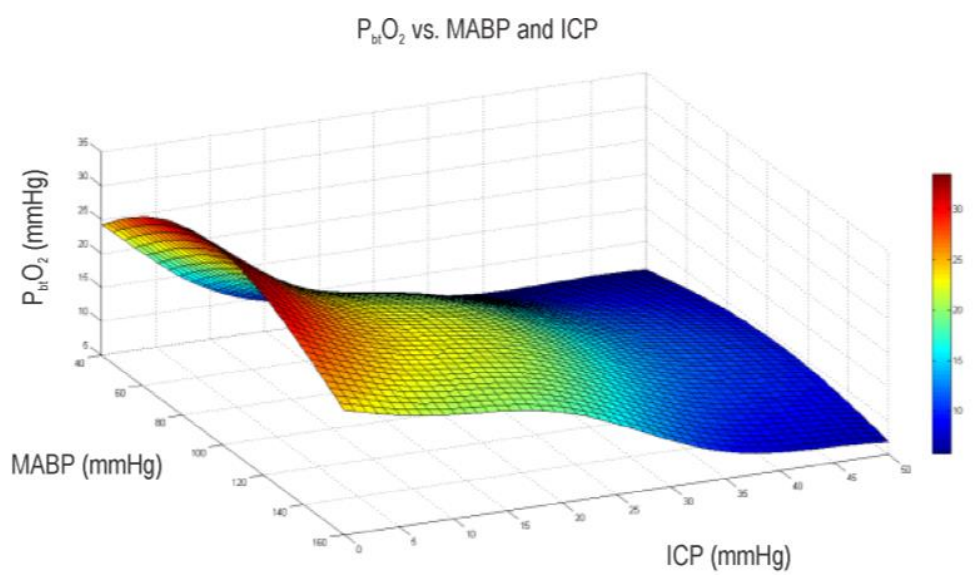

Figure 1.

3-D plot of the dynamic interrelationship between PbtO2, ICP and MABP throughout the monitoring process showing mean predicted values of $\mathrm{PbtO} 2$ as a function of ICP and MABP. The colour output reflects PbtO2 in $\mathrm{mm} \mathrm{Hg}$. This plot allows the prediction of specific $\mathrm{PbtO} 2$ values for any given ICP and MABP 


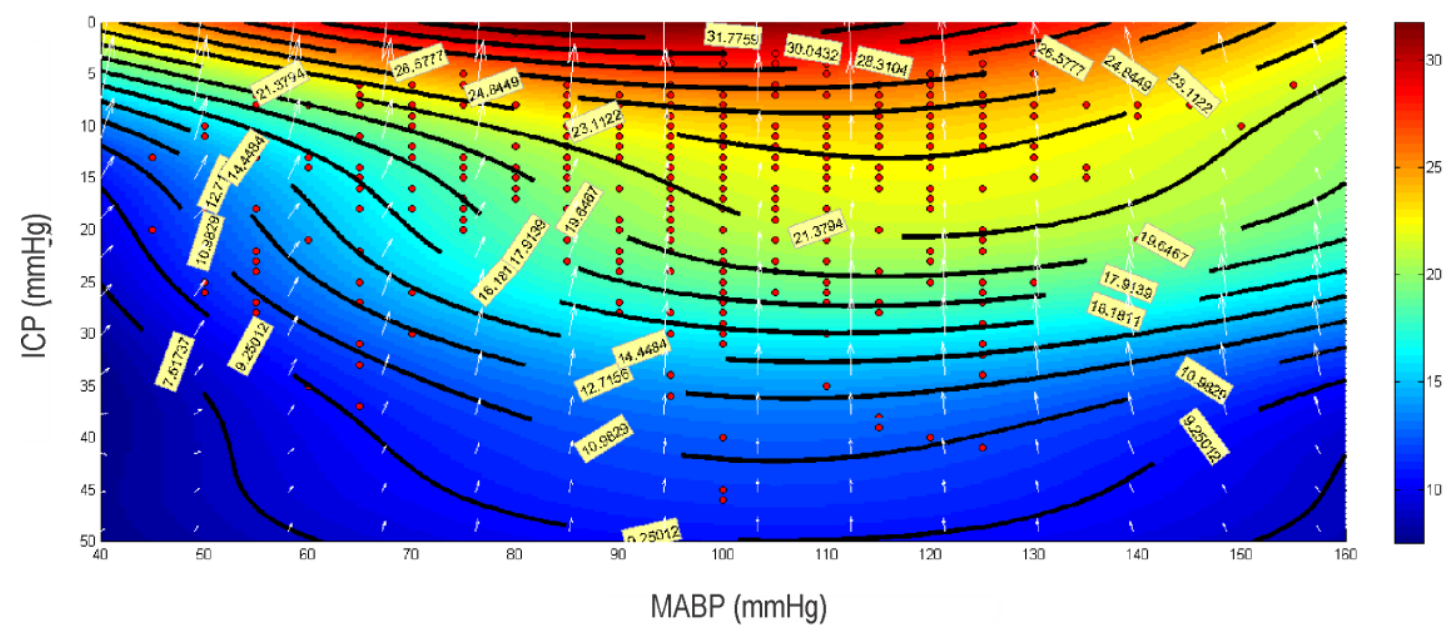

Figure 2.

Contour plot of the dynamic interrelationship between PbtO2, ICP and MABP shown in Figure 1. Black curves represent different constant $\mathrm{PbtO} 2$ values for varying values of ICP and MABP. White arrows represent the gradient of the $\mathrm{PbtO} 2$ as a function of MABP and ICP. The arrow direction for any given values of MABP and ICP indicates the sensitivity of PbtO2 to the changes of MABP or ICP. Red dots represent superimposed data points. This plot may facilitate the prediction of mean $\mathrm{PbtO} 2$ values for any given ICP and MABP during the monitoring time

Dynamic correlation between $\mathrm{PbtO} 2, \mathrm{ICP}$ and $\mathrm{CPP}$ The simultaneous 3-D analysis of the dynamic correlation between the values of $\mathrm{PbtO} 2, \mathrm{ICP}$ and CPP (Figure 3) demonstrated that $\mathrm{PbtO} 2$ was within normal range when ICP was below $5 \mathrm{~mm} \mathrm{Hg}$ and CPP was within the range of $50-150 \mathrm{~mm} \mathrm{Hg}$. $\mathrm{PbtO} 2$ was within normal range when ICP was between $5-10 \mathrm{~mm} \mathrm{Hg}$, and CPP was within the range of $60-150 \mathrm{~mm} \mathrm{Hg}$. When ICP was between 10 - $20 \mathrm{~mm} \mathrm{Hg}, \mathrm{PbtO} 2$ was normal when CPP was between $70-140 \mathrm{~mm} \mathrm{Hg}$. When ICP was between 20 - $25 \mathrm{~mm} \mathrm{Hg}, \mathrm{PbtO} 2$ was borderline normal only when CPP was within the most optimal range, which is $80-110 \pm 5 \mathrm{~mm} \mathrm{Hg}$. When $\mathrm{CPP}$ was below or above this range, the brain tissue was already hypoxic, and $\mathrm{PbtO} 2$ was below $20 \mathrm{~mm} \mathrm{Hg}$. $\mathrm{PbtO} 2$ became critical when ICP was between 30 $40 \mathrm{~mm} \mathrm{Hg}$, and life threatening when ICP was above 40 - $45 \mathrm{~mm} \mathrm{Hg}$, regardless of CPP values. We have developed a contour plot that was calculated using the same data analogous to the previous one (Figure 4). Curved lines show constant values of $\mathrm{PbtO} 2$ at varying values of ICP and CPP, and the slope of white arrows shows the significance of ICP or CPP changes on $\mathrm{PbtO} 2$ changes.

\section{$\mathrm{P}_{\mathrm{b}} \mathrm{O}_{2}$ vs. CPP and ICP}

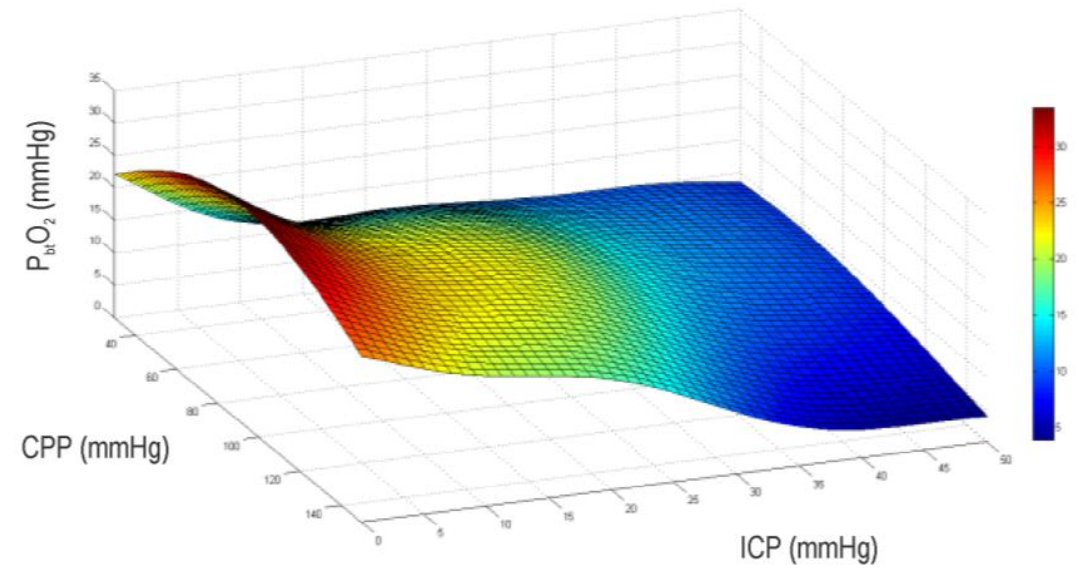

Figure 3.

3-D plot of the dynamic interrelationship between $\mathrm{PbtO} 2$, ICP and CPP throughout the monitoring process showing mean predicted values of $\mathrm{PbtO} 2$ as a function of ICP and CPP. The colour output reflects $\mathrm{PbtO} 2 \mathrm{in} \mathrm{mm}$ $\mathrm{Hg}$. This plot allows the prediction of specific $\mathrm{PbtO} 2$ values for any given ICP and CPP 


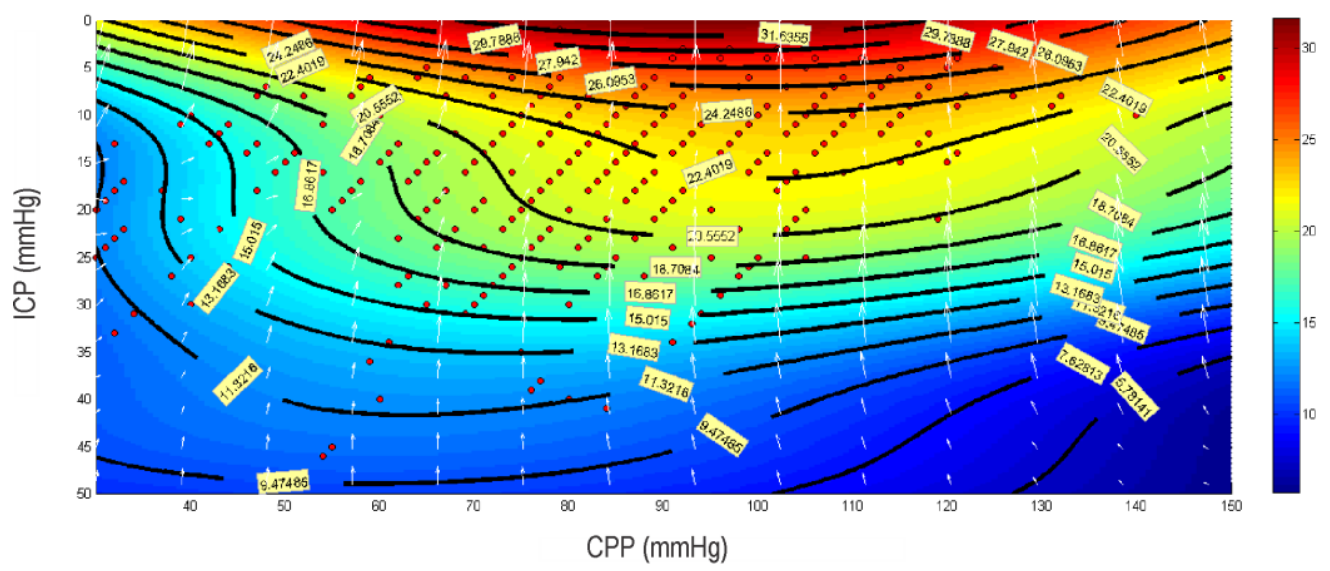

Figure 4.

Contour plot of the dynamic interrelationship between $\mathrm{PbtO}$, ICP, and CPP shown in Figure 3. Black curves represent different constant $\mathrm{PbtO} 2$ values for varying values of ICP and CPP. White arrows represent the gradient of the $\mathrm{PbtO} 2$ as a function of CPP and ICP. The arrow direction for any given values of CPP and ICP indicates the sensitivity of $\mathrm{PbtO} 2$ to the changes of CPP or ICP. Red dots represent superimposed data points. This plot may facilitate the prediction of mean $\mathrm{PbtO} 2$ values for any given ICP and $\mathrm{CPP}$ during the monitoring time

\section{Significance of ICP versus MABP for PbtO2}

The experimental data analysis by Gaussian processes showed that unit changes in the value of ICP and MABP have different effects on $\mathrm{PbtO} 2$. To evaluate the relative significance of changes of ICP and MABP on $\mathrm{PbtO} 2$ values, another contour plot (Figure 5) was computed on the basis of the 3-D data analysis presented in the previous section. The colour scale of the plot represents the significance of ICP changes over MABP changes at different ICP and MABP values on $\mathrm{PbtO} 2$. Note the inflection points in this graph at ICP values of $20 \pm 5 \mathrm{mmHg}$ and $40 \pm 5 \mathrm{mmHg}$ (Figure 5), which corresponds to capillary intravenous hydrostatic pressure and pre-capillary small arteriole hydrostatic pressure, respectively.

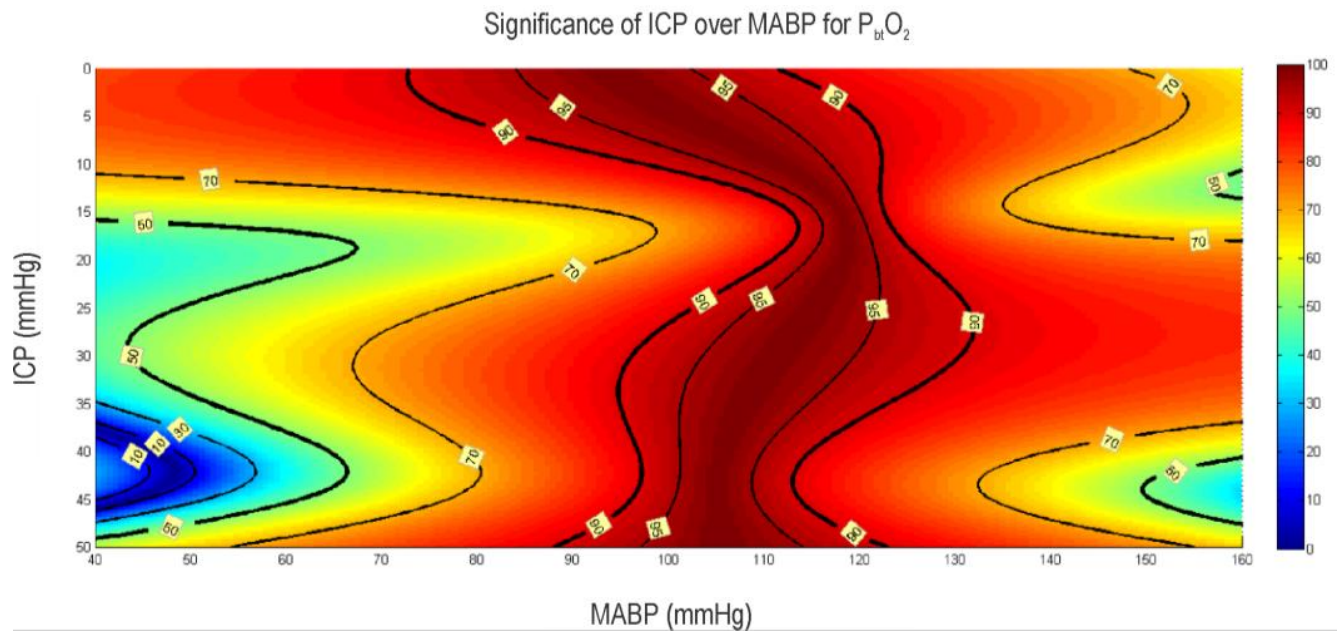

Figure 5.

Contour plot of the significance of ICP changes over MABP changes at different ICP and MABP ranges on $\mathrm{PbtO}$. Black curves represent different constant values of the significance of ICP changes over MABP changes on $\mathrm{PbtO} 2$ values. The two distinct ranges of ICP, namely $20 \pm 5 \mathrm{mmHg}$ and $40 \pm 5 \mathrm{mmHg}$, are clearly shown as inflection points in this graph. We propose that these ranges correspond to capillary intravenous hydrostatic pressure and pre-capillary small arteriole hydrostatic pressure, respectively

Significance of ICP versus $\mathrm{CPP}$ for PbtO2

The experimental data analysis by Gaussian processes showed that similar to the case of ICP and MABP, unit changes of the values of ICP and CPP have different effects on the change of $\mathrm{PbtO} 2$. Another contour plot (Figure 6) of their relative significance was computed on the basis of the 3-D data analysis presented in the previous section. The colour scale of the plot represents 
the significance of ICP changes over CPP changes at different ICP and CPP values on PbtO2. Note again the inflection points in this graph at ICP values of $20 \pm 5 \mathrm{mmHg}$ and $40 \pm 5 \mathrm{mmHg}$ (Figure 6), which again correlate to capillary intravenous hydrostatic pressure and pre-capillary small arteriole hydrostatic pressure, respectively. It is also apparent from a comparison of Figures 5 and 6 that the significance of ICP over $\mathrm{CPP}$ is distinctively more than that over MABP.

Significance of ICP over CPP for $\mathrm{P}_{\mathrm{t}} \mathrm{O}_{2}$

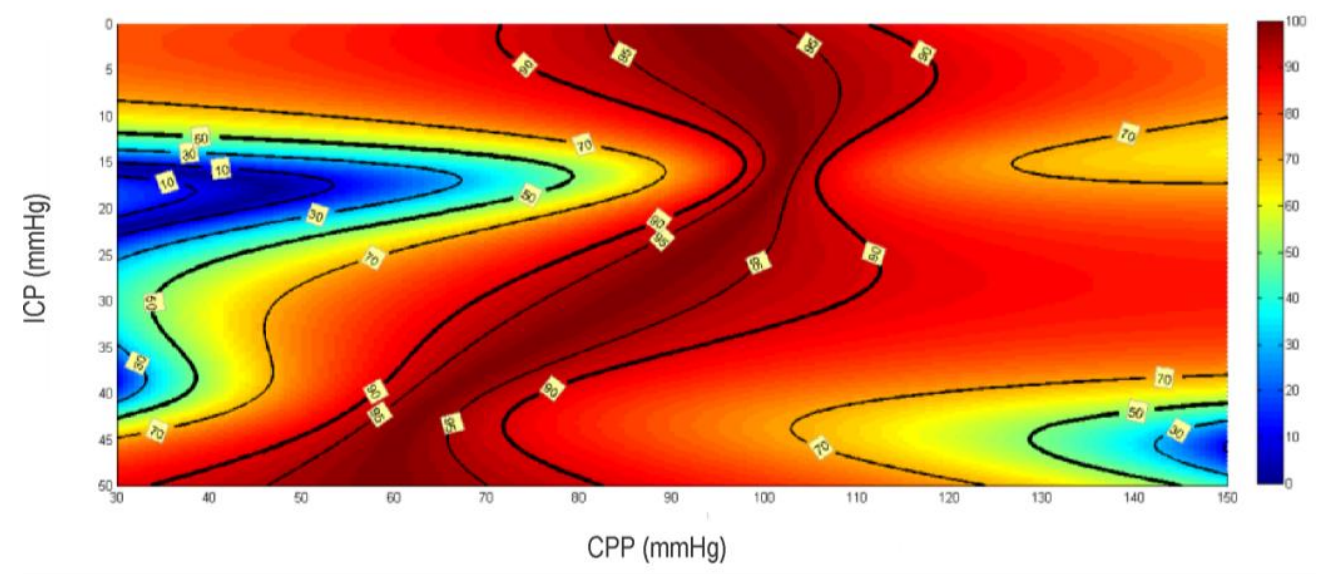

Figure 6.

Contour plot of the significance of ICP changes over CPP changes at different ICP and CPP ranges on PbtO2. Black curves represent different constant values of the significance of ICP changes over CPP changes on $\mathrm{PbtO} 2$ values. The two distinct ranges of ICP, namely $20 \pm 5 \mathrm{mmHg}$ and $40 \pm 5 \mathrm{mmHg}$, are clearly seen as inflection points in this graph. We propose that these ranges correspond to capillary intravenous hydrostatic pressure and pre-capillary small arteriole hydrostatic pressure, respectively

\section{Critical thresholds of ICP}

Both clinical and experimental studies have shown two distinct thresholds for ICP, that is $20-25 \mathrm{mmHg}$ and $35-40 \mathrm{mmHg}$, which are strongly correlated to critical and life-threatening levels of brain tissue oxygenation, respectively [4, 17, 24, 37, 46, 48, 55]. Previous studies have demonstrated that the ovine model of TBI replicates many features of human TBI [60] including correlations between ICP and $\mathrm{PbtO} 2$ as well as similar thresholds for ICP. Therefore in this study we tried to elucidate the critical thresholds of ICP and the correlation between ICP thresholds and $\mathrm{PbtO} 2$.

It is well known that the mean intravascular hydrostatic pressure in post-capillary venules is $10-15 \mathrm{mmHg}$, in capillaries it is $20-25 \mathrm{mmHg}$, and in pre-capillary arterioles is $35-40 \mathrm{mmHg}[7,10]$ (Table I). Normal ICP values are considered to be less than 10 to 15 $\mathrm{mmHg}$ for adults and an ICP greater than $15 \mathrm{mmHg}$ is considered to be abnormal [4, 28, 37, 47]. Our study has shown that $\mathrm{PbtO} 2$ was within normal limits (> $20 \mathrm{mmHg}$ ) when ICP was less than $20 \mathrm{mmHg}$, $\mathrm{PbtO} 2$ was critically low when ICP was above 20 $25 \mathrm{mmHg}$, and $\mathrm{PbtO} 2$ was life-threatening when ICP was above 35 - $40 \mathrm{mmHg}$ (Figure 1). We consider that $\mathrm{PbtO} 2$ changes from normal $(>20 \mathrm{mmHg}$ ) to critical $(<10-15 \mathrm{mmHg})$ to life-threatening $(<10$ $\mathrm{mmHg})$ when ICP changes from normal $(<10-15$ $\mathrm{mmHg}$ ) to critical $(20-25 \mathrm{mmHg})$ to life-threatening (> $35-40 \mathrm{mmHg}$ ), are reflecting the different intra- vascular hydrostatic pressures in different segments of the cerebral vasculature. These thresholds would be related to the successive compression of postcapillary venules, capillaries and pre-capillary metarterioles by increasing ICP.

Table I

Mean Hydrostatic pressure values in cerebral postcapillary venules, capillaries, and pre-capillary met-

\begin{tabular}{|l|r|}
\hline Post capillary venules & $15-20 \mathrm{mmHg}$ \\
\hline Capillaries & $20-25 \mathrm{mmHg}$ \\
\hline Pre-capillary met-arterioles & $35-40 \mathrm{mmHg}$ \\
\hline
\end{tabular}

The first ICP threshold of 20 - $25 \mathrm{mmHg}$ is critical because at this level, ICP can already compress capillaries and compromise the blood flow. The second ICP threshold of 35 - $40 \mathrm{mmHg}$ would be considered life-threatening because at this level ICP in addition can compress and even close the precapillary met-arterioles and dramatically decrease $\mathrm{CBF}$ and so $\mathrm{PbtO} 2$. Therefore, as ICP increases after TBI, it would sequentially compress and significantly constrict postcapillary venules (when ICP is $15-20 \mathrm{mmHg}$ ), then capillaries (when ICP is $20-25 \mathrm{mmHg}$ ), and finally as it goes above $35-40 \mathrm{mmHg}$, it would compress precapillary met-arterioles and small arterioles (Table I). The three step pattern in Figure 1 clearly reflects these pathophysiological changes occurring as ICP increases, with the thresholds corresponding to intra- 
vascular hydrostatic pressure differences in the above mentioned segments of the cerebral vascular bed. This is the first time that $\mathrm{PbtO} 2, \mathrm{ICP}$ and MABP or CPP have been analysed simultaneously with machine learning using Gaussian processes 3-D, and to the best of our knowledge, it is also the first time that a contour plot (chart) has been developed describing the dynamic interrelationship between $\mathrm{PbtO} 2, \mathrm{ICP}$, and MABP or CPP. The similarity in responses between our ovine model of TBI and human TBI has been critical to this development, and it underscores the importance of large animal models of TBI for translational research. The advantage of the simultaneous 3-D analysis of the interrelationship between $\mathrm{PbtO} 2$, ICP, and CPP, compared to analysis of only 2 parameters $(\mathrm{PbtO} 2$ vs. ICP, or $\mathrm{PbtO} 2$ vs. $\mathrm{CPP})$ is that it reveals the impact of ICP on $\mathrm{PbtO} 2$ and CPP independently, while 2 parameter analyses overlooks the impact of ICP on both CPP and $\mathrm{PbtO} 2$. The reason for this difference is that 3-D analysis considers the correlation between CPP and ICP (CPP being a derivative of ICP) as well as revealing the simultaneous correlation of $\mathrm{PbtO} 2$ independently with both $\mathrm{CPP}$ and ICP. The 3-D analysis clearly showed that $\mathrm{PbtO} 2$ values depend on ICP more than on CPP when ICP increases above its critical threshold (20 - $25 \mathrm{mmHg}$ ), and therefore increases in CPP above 70 - $75 \mathrm{mmHg}$ are ineffective for the improvement of $\mathrm{PbtO} 2$ when ICP is above these levels.

Reconsidering the formula for calculation of CPP CPP is the pressure gradient acting across the cerebrovascular bed and is regarded as a main determinant of CBF. To date, the question of what the optimal CPP is following TBI remains unanswered [3, 22]. Indeed, when CPP is vigorously maintained above $70 \mathrm{mmHg}$, there is no significant benefit to patients and often systemic complications may occur, including cardiovascular and respiratory complications [3]. Paradoxically, a level of CPP below $60 \mathrm{mmHg}$ is considered by some to be detrimental [6]. When the formula for CPP was first proposed, it was based on the assumption that autoregulation was disrupted and cerebral blood flow became linearly related to MABP; later studies, however, have revealed that autoregulation is functioning in more than $75 \%$ of patients with severe TBI [9, 36].

Normally autoregulation maintains constant cerebral post-arteriolar pressure (PAP) at $35 \pm 5 \mathrm{mmHg}[7,10]$. When ICP is not increased (ICP $=5 \pm 5 \mathrm{mmHg}$ ), the real cerebral perfusion pressure will actually be the difference between PAP and ICP (CPP = PAP - ICP) and would normally be maintained at $30 \pm 5 \mathrm{mmHg}$. Since pressure autoregulation is functioning in the majority of patients with severe TBI, this means that CPP values are the difference between PAP and ICP, rather than between MABP and ICP. This may explain why, to date, it has been unclear how the same CPP values in different patients with TBI maintain different
$\mathrm{PbtO} 2$ values, and why increases in CPP only improve $\mathrm{PbtO} 2$ in some patients and not in others.

Increasing CPP to 70 - $80 \mathrm{mmHg}$ will improve $\mathrm{PbtO} 2$ only when ICP is below its critical threshold level (ICP $<25-30 \mathrm{mmHg}$ ) and MABP is below 100 $110 \mathrm{mmHg}$. When ICP is above $35-40 \mathrm{mmHg}$, there is no improvement in $\mathrm{PbtO} 2$ when CPP is increased. We consider that regardless of MABP/CPP values, intravascular hydrostatic pressure in post-arterioles cannot be increased significantly above $35-40 \mathrm{mmHg}$. Therefore, ICP values above $35-40 \mathrm{mmHg}$ are critical as they can overcome the intravascular pressure and compress capillaries and pre-capillary met-arterioles. In this scenario, even though CPP values calculated by currently used formulae can be maintained at normal levels $(60-70 \mathrm{mmHg})$ with the help of increased MABP, nonetheless $\mathrm{PbtO} 2$ values still will be critically low since the real cerebral perfusion pressure, that is $\mathrm{CPP}=\mathrm{PAP}$ - ICP, will be closer to zero.

It is therefore clear that CPP values calculated with the currently used formula under conditions when ICP is above the critical threshold do not reflect the real value of CPP and its real correlation to $\mathrm{PbtO} 2$, and overlooks the impact of ICP on CPP and PbtO2. $\mathrm{PbtO} 2$ is still critically low under these conditions. This may explain why patients with the same CPP values can often have different $\mathrm{PbtO} 2$ values and outcomes. In contrast, if CPP values are calculated as the difference between PAP and ICP, the value of the revised CPP would clearly reflect the real state of cerebral perfusion and of $\mathrm{PbtO} 2$. Therefore we propose a modified formula, which considers the impact of ICP on both CPP and $\mathrm{PbtO} 2$, and so reveals the real dynamic interrelationship between these three parameters, that is; CPP $=$ PAP - ICP, where MABP is replaced by PAP, which represents the post-arteriolar pressure.

\section{Conclusions}

Simultaneous 3-D analysis can reveal not only a correlation between $\mathrm{PbtO} 2$ and ICP or MABP or CPP separately, but also the simultaneous dynamic interrelationship between $\mathrm{PbtO} 2$, ICP and MABP or CPP that two-parameter analysis cannot. The two ICP thresholds observed in our sheep model of TBI correlated to clinically observed human data, and associated to two different intravascular hydrostatic pressures in cerebral capillaries and pre-capillary small arterioles. 3-D analysis has allowed us to develop a chart (contour plot) of the dynamic interrelationship between $\mathrm{PbtO} 2$, ICP, and MABP, which when calculated and developed by using human data, has the potential to have clinical application in the management of patients with TBI to achieve an optimal CBF and so $\mathrm{PbtO} 2$. And in conclusion, the current formula of CPP may overlook the real values of ICP and MABP, therefore we propose that the formula be modified 
to $\mathrm{CPP}=\mathrm{PAP}$ - ICP, where MABP is replaced by PAP: post arteriolar pressure.

\section{Acknowledgement}

This work was supported, in part, by the Australian National Health and Medical Research Council and the Neurosurgical Research Foundation (Adelaide). The authors thank Professor Robert Vink for his support and helpful comments and Dr Emma Thornton for her assistance during some of the experiments. This work has some inclusion of content from the $\mathrm{PhD}$ thesis [15] by the author Levon Gabrielian which represents the only medium it has appeared in, is in line with the author's university policy, and can be accessed online.

\section{Conflict of interest}

The authors declare no conflict of interest.

\section{References}

1. Ang BT, Wong J, Lee KK, Wang E, Ng I, Temporal changes in cerebral tissue oxygenation with cerebrovascular pressure reactivity in severe traumatic brain injury. J Neurol Neurosurg Psychiatry., 2007; 78: 298-302.

2. Azman K, Kocijan J, Non-linear model predictive control for models with local information and uncertainties. Transactions of the Institute of Measurement and Control., 2008; 30: 5: 371-396.

3. Bruns JJr, Hauser WA, The epidemiology of traumatic brain injury: a review. Epilepsia., 2003; 44(10): 2-10.

4. Carney N, Totten AM, O'Reilly C, Ullman JS, Hawryluk GWJ, Bell MJ, Bratton SL, Chesnut R, Harris OA, Kissoon N, Rubiano AM, Shutter L, Tasker RC, Vavilala MS, Wilberger J, Wright DW, Ghajar J, Guidelines for the management of severe traumatic brain injury. Neurosurgery., 2017; 80(1): 6-15.

5. Chesnut RM, Secondary brain insult after head injury: clinical perspectives. New Horiz, 1995; 3(3): 366-375.

6. Clifton GL, Miller ER, Choi SC, Levin HS, Fluid thresholds and outcome from severe brain injury. Crit Care Med., 2002; 30: 739-745.

7. Costanzo L, Physiology, $4^{\text {th }}$ ed. Sounders, Elsevier: Philadelphia; 2010: 120-123.

8. Cremer OL, van Dijk GW, van Wensen E, Brekelmans GJ, Moons KG, Leenen LP, Kalkman CJ, Effect of intracranial pressure monitoring and targeted intensive care on functional outcome after severe head injury. Crit Care Med., 2005; 33: 2207-2213.

9. Czosnyka M, Balestreri M, Steiner L, Smielewski P, Hutchinson PJ, Matta B, Pickard JD, Age, intracranial pressure, autoregulation, and outcome after brain trauma. J Neurosurgery., 2005; 102: 450-454.

10. Despopoulos A, Silbernagl S, Color Atlas of Physiology, $4^{\text {th }}$ ed., G Thieme Verlag, Stuttgart; 1991: 156-159.

11. Donnelly J, Czosnyka M, Adams H, Robba C, Steiner LA, Cardim D, Cabella B, Liu X, Ercole A, Hutchinson PJ, Menon DK, Aries MJH, Smielewski $\mathrm{P}$, Individualising thresholds of cerebral perfusion pressure using estimated limits of autoregulation. Crit Care Med., 2017; 45(9): 1464-1471.

12. Figaji AA, Zwane E, Fieggen AG, Argent AC, Le Roux PD, Siesjo P, Peter JC, Pressure autoregulation, intracranial pressure, and brain tissue oxygenation in children with severe traumatic brain injury. $J$ Neurosurg Pediatr., 2009; 4: 420-428.

13. Finfer SR, Cohen J, Severe traumatic brain injury. Resuscitation., 2001; 48: 77-90.

14. Fleminger S, Ponsford J, Long term outcome after traumatic brain injury. BMJ., 2005; 331: 1419-1420.

15. https://digital.library.adelaide.edu.au.

16. Gregorcic G, Lightbody G, Gaussian process approach for modeling of nonlinear systems. Engine Applic Artif Intellig.., 2009; 22: 522-533.

17. Grinkeviciute DE, Kevalas R, Matukevicius A, Ragaisis $\mathrm{V}$, Tamasauskas A, Significance of intracranial pressure and cerebral perfusion pressure in severe pediatric traumatic brain injury. Medicina (Kaunas), 2008; 44: 119-125.

18. Harris C, DiRusso S, Sullivan T, Benzil DL, Mortality risk after head injury increases at 30 years. $J$ Am Coll Surg., 2003; 197: 711-716.

19. Helmy A, Vizcaychipi M, Gupta AK, Traumatic brain injury: intensive care management. Br J Anaesth., 2007; 99: 32-42.

20. Horváth E, Orădan A, Chiriac L, Dobreanu M, Nagy EE, Voidăzan S, Berei R, Muntean DL, Huțanu A, Fish-oil preconditioning up-regulates expression of splenic ARG1positive M2 type macrophages and the ARG1/INOS2 ratio after experimental induced transient cerebral ischemia. Farmacia, 2019; 67(5): 820-829.

21. Hlatky R, Valadka AB, Robertson CS, Intracranial pressure response to induced hypertension: role of dynamic pressure autoregulation. J Neurosurg., 2005; 57: 917-923.

22. Howells T, Elf K, Jones PA, Ronne-Engstrom E, Piper I, Nilsson P, Andrews P, Enblad P, Pressure reactivity as a guide in the treatment of cerebral perfusion pressure in patients with brain trauma. $J$ Neurosurg., 2005; 102: 311-317.

23. Langlois JA, Rutland-Brown W, Wald MM, The epidemiology and impact of traumatic brain injury: a brief overview. J Head Trauma Rehabil., 2006; 21: 375-378.

24. Le Roux P, Intracranial Pressure Monitoring and Management. In: Laskowitz D, Grant G, editors. Translational Research in Traumatic Brain Injury. Boca Raton (FL): CRC Press/Taylor and Francis Group; 2016.

25. Lewis SB, Finnie JW, Blumbergs PC, Scott G, Manavis J, Brown C, Reilly PL, Jones NR, McLean AJ, A head impact model of early axonal injury in the sheep. $J$ Neurotrauma., 1996; 13: 505-514.

26. Marmarou A, Increased intracranial pressure in head injury and influence of blood volume. J Neurotrauma., 1992; 9(1): 327-332.

27. Marmarou A, Saad A, Aygok G, Rigsbee M, Contribution of raised ICP and hypotension to CPP reduction in severe brain injury: correlation to outcome. Acta Neurochir., 2005; 95: 277-280. 
28. Mazzola CA, Adelson PD, Critical care management of head trauma in children. Crit Care Med., 2002; 30: S393-401.

29. Morris KP, Forsyth RJ, Parslow RC, Tasker RC, Hawley CA, Intracranial pressure complicating severe traumatic brain injury in children: monitoring and management. Intens Care Med., 2006; 32: 1606-1612.

30. Murray CJ, Lopez AD, Alternative projections of mortality and disability by cause 1990-2020: Global Burden of Disease Study. Lancet, 1997; 349: 1498-1504.

31. Nangunoori R, Maloney-Wilensky E, Stiefel M, Park S, Andrew Kofke W, Levine JM, Yang W, Le Roux PD, Brain tissue oxygen-based therapy and outcome after severe traumatic brain injury: a systematic literature review. Neurocrit Care., 2012; 17: 131-138.

32. Narotam PK, Burjonrappa SC, Raynor SC, Rao M, Taylon $\mathrm{C}$, Cerebral oxygenation in major pediatric trauma: its relevance to trauma severity and outcome. J Pediatr Surg., 2006; 41: 505-513.

33. Panerai RB, Kerins V, Fan L, Yeoman PM, Hope T, Evans DH, Association between dynamic cerebral autoregulation and mortality in severe head injury. Br J Neurosurg., 2004; 18: 471-479.

34. Panerai RB, Assessment of cerebral pressure autoregulation in humans--a review of measurement methods. Physiol Meas., 1998; 19: 305-338.

35. Pascual JL, Georgoff P, Maloney-Wilensky E, Sims C, Sarani, B, Stiefel MF, LeRoux PD, Schwab CW, Reduced brain tissue oxygen in traumatic brain injury: are most commonly used interventions successful?. J Trauma., 2011; 70: 535-546.

36. Peterson E, Chesnut RM, Static autoregulation is intact in majority of patients with severe traumatic brain injury. J Trauma., 2009; 67: 944-949.

37. Rangel-Castilla L, Gopinath S, Robertson CS, Management of intracranial hypertension. Neurol Clin., 2008; 26: 521-541.

38. Rasmussen CE, Williams CKI, Gaussian Processes for Machine Learning. MIT Press, Cambridge; 2006.

39. Reithmeier T, Lohr M, Pakos, P, Ketter G, Ernestus $\mathrm{RI}$, Relevance of ICP and ptiO2 for indication and timing of decompressive craniectomy in patients with malignant brain edema. Acta Neurochir., 2005; 147: 947-951.

40. Resnick DK, Marion DW, Carlier P, Outcome analysis of patients with severe head injuries and prolonged intracranial hypertension. JTrauma., 1997; 42: 1108-1111.

41. Rosner MJ, Rosner SD, Johnson AH, Cerebral perfusion pressure: management protocol and clinical results. J Neurosurg., 1995; 83: 949-962.

42. Sankhyan N, Vykunta Raju KN, Sharma S, Gulati S, Management of raised intracranial pressure. Indian J Pediatr., 2010; 77: 1409-1416.

43. Sarrafzadeh AS, Kiening KL, Callsen TA, Unterberg $\mathrm{AW}$, Metabolic changes during impending and manifest cerebral hypoxia in traumatic brain injury. $\mathrm{Br} J$ Neurosurg., 2003; 17: 340-346.

44. Seeger M, Gaussian processes for machine learning. Int J Neural Syst., 2004; 14: 69-106.

45. Signorini DF, Andrews PJ, Jones PA, Wardlaw JM, Miller JD, Adding insult to injury: the prognostic value of early secondary insults for survival after traumatic brain injury. J Neurol Neurosurg Psych., 1999; 66: 26-31.

46. Singhi SC, Tiwari L, Management of intracranial hypertension. Indian J Pediat., 2009; 76: 519-529.

47. Smith M, Monitoring intracranial pressure in traumatic brain injury. Anaesth Analg., 2008; 106: 240-248.

48. Steiner LA, Andrews PJ, Monitoring the injured brain. ICP and CBF. Br J Anaesth., 2006; 97: 26-38.

49. Stiefel MF, Spiotta A, Gracias VH, Garuffe AM, Guillamondegui O, Maloney- Wilensky E, Bloom S, Grady MS, LeRoux PD, Reduced mortality rate in patients with severe traumatic brain injury treated with brain tissue oxygen monitoring. J Neurosurg., 2005; 103: 805-811.

50. Stiefel MF, Udoetuk JD, Spiotta AM, Gracias VH, Goldberg A, Maloney-Wilensky E, Bloom S, Le Roux PD, Conventional neurocritical care and cerebral oxygenation after traumatic brain injury. $J$ Neurosurg., 2006; 105: 568-575.

51. Stiefel MF, Udoetuk JD, Storm PB, Sutton LN, Kim $\mathrm{H}$, Dominguez, TE, Helfaer MA, Huh J, Brain tissue oxygen monitoring in pediatric patients with severe traumatic brain injury. J Neurosurg., 2006; 105: 281-286.

52. Struchen MA, Hannay HJ, Contant CF, Robertson CS, The relation between acute physiological variables and outcome on the Glasgow Outcome Scale and Disability Rating Scale following severe traumatic brain injury. J Neurotrauma., 2001; 18: 115-125.

53. Su Z, Ye L, An intelligent signal processing and pattern recognition technique for defect identification using an active sensor network. Smart Mater Struct., 2004; 13: 957-969.

54. Tolias CM, Bullock MR, Critical appraisal of neuroprotection trials in head injury: what have we learned? NeuroRx., 2004; 1: 71-79.

55. Treggiari MM, Schultz N, Yanez ND, Romand JA, Role of intracranial pressure values and patterns in predicting outcome in traumatic brain injury: a systematic review. Neurocrit Care., 2007; 6(2): 104-112.

56. Unterberg AW, Stover J, Kress B, Kiening KL, Edema and brain trauma. Neuroscience., 2004; 129: 1021-1029.

57. Van den Brink WA, van Santbrink H, Steyerberg EW, Avezaat CJ, Suazo JA, Hogesteeger C, Jansen WJ, Kloos LM, Vermeulen J, Maas AI, Brain oxygen tension in severe head injury. J Neurosurg., 2000; 46: 868-876.

58. Van den Heuvel C, Blumbergs PC, Finnie JW, Manavis J, Jones NR, Reilly PL, Pereira RA, Upregulation of amyloid precursor protein messenger RNA in response to traumatic brain injury: an ovine head impact model. Exper Neurology., 1999; 159: 441-450.

59. Van Santbrink H, vd Brink W., Steyerberg EW, Carmona Suazo JA, Avezaat CJ, Maas AI, Brain tissue oxygen response in severe traumatic brain injury. Acta Neurochir., 2003; 145: 429-438.

60. Vink R, Bahtia KD, Reilly PL, The relationship between intracranial pressure and brain oxygenation following traumatic brain injury in sheep. Acta Neurochir., 2008; 102: 189-192.

61. Vink R, Nimmo AJ, Multifunctional drugs for head injury. Neurotherapeutics., 2009; 6: 28-42. 